\title{
Evaluation of Domestication Loci Associated with Awnlessness in Cultivated Rice, Oryza sativa
}

\author{
Yaddehige Priya Jayantha Amarasinghe ${ }^{1}$, Rie Kuwata', Akinori Nishimura', Phuong Dang Thai Phan ${ }^{1,2}$,
} Ryo Ishikawa ${ }^{1}$ and Takashige Ishii ${ }^{* *}$

\begin{abstract}
Background: Awns are bristle-like organs at the tips of the glumes. Wild rice has maintained long awns for successful seed propagation through seed dispersal. Seed awning is an interesting trait in rice domestication. Long awns might have been beneficial for seed gatherers in the initial phase of domestication; however, awnless phenotypes were preferably selected in a later phase with non-seed-shattering plants. Investigation of domestication loci associated with awnlessness in cultivated rice will be useful in clarifying the process and history of rice domestication.

Results: Quantitative trait locus (QTL) analysis for seed awning was carried out using a $\mathrm{BC}_{3} \mathrm{~F}_{2}$ population between Oryza sativa IR36 (a cultivated donor parent with awnless phenotype) and O. rufipogon W630 (a wild recurrent parent with awns). As a result, two QTLs on chromosome 4 (corresponding to An-1 and LABA1) and one on chromosome 2 (designated as qAWNL2) were detected. Gene interaction among three seed-awning QTLs were further examined with the plants having eight different combinations of homozygous genotypes. Their awn length variation indicated that the IR36 alleles at these loci had the additive awnlessness effects in the genetic background of wild rice. The shortest awn length was observed for the plants having IR36 homozygous alleles at all loci, giving about 75\% reduction in awn length. By the fine mapping, the candidate region of the novel qAWNL2 locus was delimited in a 157.4-kb region containing 22 predicted genes in Nipponbare genome.

Conclusions: QTL analysis revealed that three loci, An-1, LABA1 and qAWNL2, were mainly responsible for the awnlessness of $O$. sativa IR36. In the wild genetic background, loss-of-function alleles at three awning loci showed additive effects on length reduction. In rice domestication, awnless forms may be gradually generated through the accumulation of mutations at awning loci.
\end{abstract}

Keywords: Awn, Awnlessness, Domestication, Gene interaction, Oryza rufipogon, QTL mapping, Rice

\section{Background}

Crop domestication which formed the basis for agriculture, has been considered a major turning point in human history (Fuller and Allaby 2009). In the transition from gathering to cultivation, early farmers selected wild plants with useful genetic modifications and developed

\footnotetext{
* Correspondence: tishii@kobe-u.ac.jp

${ }^{1}$ Graduate School of Agricultural Science, Kobe University, 1-1 Rokkodai,

Nada-ku, Kobe 657-8501, Japan

Full list of author information is available at the end of the article
}

improved populations with desirable traits (Vaughan et al. 2007). In cereals, non-seed-shattering behavior is a conspicuous trait distinguishing wild and cultivated forms, and an important adaptation syndrome resulting from automatic selection through harvesting (Harlan et al. 1973).

Rice (Oryza sativa L.) is a major food crop and a primary food source for approximately half of the world's population (Zeigler and Barclay 2008). This crop was domesticated from the Asian wild species, O. rufipogon

\section{Springer Open}

(๑) The Author(s). 2020 Open Access This article is licensed under a Creative Commons Attribution 4.0 International License, which permits use, sharing, adaptation, distribution and reproduction in any medium or format, as long as you give appropriate credit to the original author(s) and the source, provide a link to the Creative Commons licence, and indicate if changes were made. The images or other third party material in this article are included in the article's Creative Commons licence, unless indicated otherwise in a credit line to the material. If material is not included in the article's Creative Commons licence and your intended use is not permitted by statutory regulation or exceeds the permitted use, you will need to obtain permission directly from the copyright holder. To view a copy of this licence, visit http://creativecommons.org/licenses/by/4.0/. 
Griff (Oka 1988). Wild rice possesses several propagation-related traits, such as prostrate growth, seed shattering, open panicle structure, seed awning, and the ability to outcross. A reduction in seed shattering was a key trait for the emergence of cultivated rice because it directly enhanced the collection efficiency for ancient seed gatherers (Harlan et al. 1973).

In rice, three natural variants in the seed-shattering loci (sh4, qSH1 and $q S H 3$ ) have been reported (Li et al. 2006; Konishi et al. 2006; Htun et al. 2014). In the genetic background of cultivated rice, the wild functional alleles at two major loci, sh4 and qSH1, show seedshattering effects. However, in the genetic background of wild rice, the cultivated alleles at either locus do not lead to non-shattering phenotypes (Ishikawa et al. 2010; Htun et al. 2014). This suggests that wild rice has other minor genes associated with seed shattering. Nonshattering plants are not easily identified in wild rice populations. Previously, we found that a simple morphological change in panicle shape (from open to closed), controlled by a single locus of SPR3, led to a reduction in seed shedding in wild rice (Ishii et al. 2013). In wild plants with closed panicles, the upper mature seeds are temporarily retained by the support of long awns from lower immature seeds. Since this panicle shape change results in higher seed collection efficiency (Ishii et al. 2013), seed awning may have been a beneficial trait for seed gatherers in the initial phase of domestication. Interestingly, long awns on closed panicles also hinder free exposure to anthers and stigmas during the flowering stage. This may enhance self-pollination and the accumulation of recessive alleles at the seed-shattering loci. After the emergence of non-seed-shattering plants, seed awning may have become an undesirable trait because long awns disturb seed harvesting and handling (Ishii and Ishikawa 2018).

Awns are bristle-like organs at the tips of the glumes. Wild rice has retained long awns for successful seed propagation through seed dispersal. There are three major loci, $A n-1, L A B A 1$ and $R A E 2$, for seed awning in wild rice (Luo et al. 2013; Hua et al. 2015; BesshoUehara et al. 2016). At these loci, wild functional alleles worked for seed awning in cultivated rice, but cultivated loss-of-function alleles did not contribute much to awn length reduction in wild rice (Ikemoto et al. 2017). These allele effects are similar to those which control seed shattering in the genetic background of wild rice, indicating that other minor loci are associated with these wild traits.

Seed awning is an interesting trait in rice domestication. Long awns might have been beneficial for seed gatherers in the initial phase of domestication; however, awnless phenotypes were preferably selected in a later phase with non-seed-shattering plants. In this study, first, a quantitative trait locus (QTL) analysis for awnlessness was carried out using a wild backcrossed population between O. sativa IR36 and O. rufipogon W630. Then, gene interactions at these loci were examined along with causal gene estimation, in order to clarify the genetic mechanisms of awnlessness in cultivated rice.

\section{Materials and Methods}

\section{Plant Materials}

A long-awned accession of O. rufipogon W630 and an awnless cultivar of $O$. sativa IR36 were used in this study
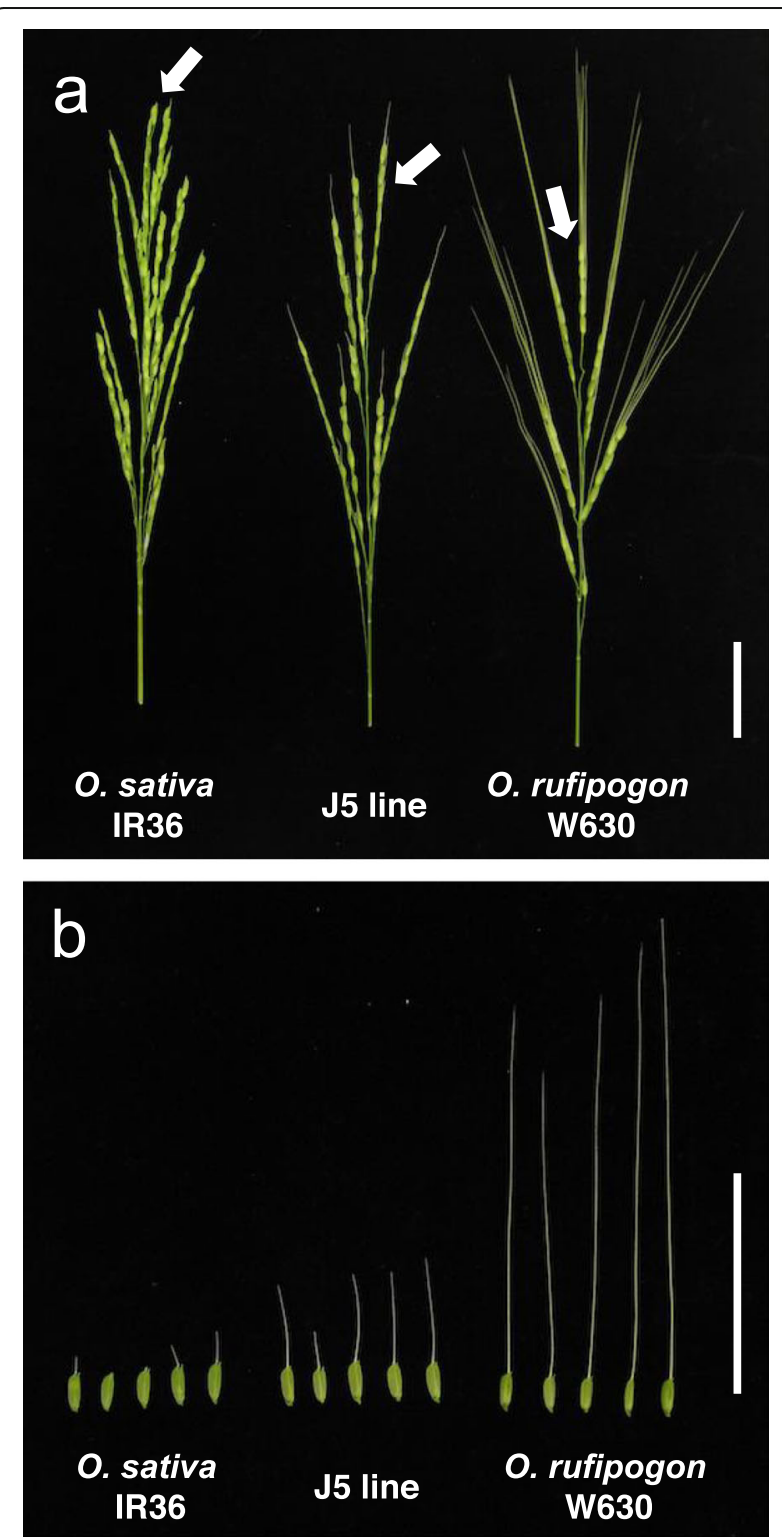

Fig. 1 Panicle and spikelet morphology of the O. sativa IR36, J5 line and O. rufipogon W630. a Whole panicles. Arrows indicate top primary branches in the panicles. $\mathbf{b}$ Spikelets on the top primary branches. The 1st to 5th spikelets are arranged from left to right. Scale bar: $5 \mathrm{~cm}$ 
(Fig. 1). This wild accession was provided by the $\mathrm{Na}$ tional Institute of Genetics, Japan. IR36 is one of the most popular Indica cultivars released from International Rice Research Institute (Khush and Virk 2005). A single plant of $O$. sativa IR36 was crossed three times with O. rufipogon W630, and 146 backcross recombinant inbred lines (BILs) were developed at the $\mathrm{BC}_{2} \mathrm{~F}_{7}$ generation by the single-seed-descendant method (Fig. 2). Since they had the genetic background of wild rice, all the BILs had awned seeds. Among them, a single line J5 had the shortest awns and was selected to examine the awning loci (Fig. 1). The J5 line was crossed with W630, and $184 \mathrm{BC}_{3} \mathrm{~F}_{2}$ plants were produced (Fig. 2). They were phenotypically evaluated in the paddy field for the awn length variation. The progenies from the selected $\mathrm{BC}_{3} \mathrm{~F}_{2}$ plants were further used for the evaluation of gene interaction and fine mapping.

\section{Evaluation of Awn Length}

In wild rice, awn length varies according to the spikelet position in the panicle (Fig. 1a) (Ikemoto et al. 2017), and the seeds shatter in the mature stage. Therefore, the upper 1st to 5 th spikelets on the top primary branch in a panicle were collected in the flowering stage, and their awn lengths were measured (Fig. 1b). The averages of five panicles were calculated for each plant.

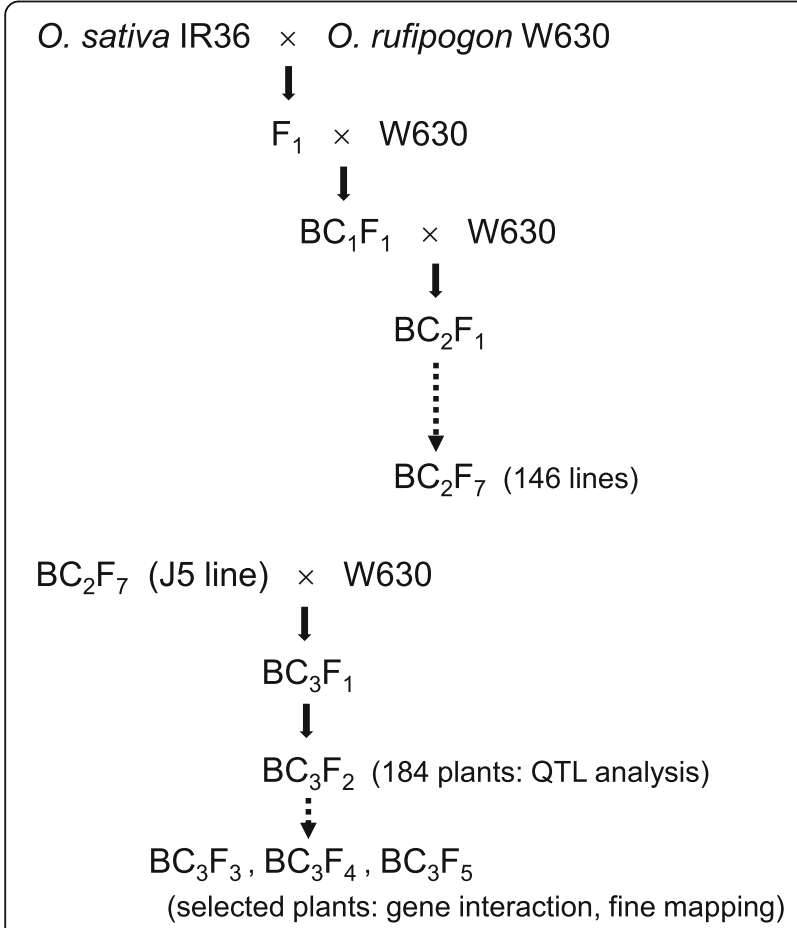

Fig. 2 Pedigree of backcross recombinant inbred lines between $O$. sativa IR36 and O. rufipogon W630. A single line of J5 was further backcrossed with W630, and their $B C_{3}$ progenies were used for the genetic analysis

\section{QTL Analysis for Seed Awning}

Total DNA was extracted from the $\mathrm{J} 5$ line at the $\mathrm{BC}_{2} \mathrm{~F}_{7}$ generation by the potassium acetate method (Dellaporta et al. 1983), and the marker genotypes were surveyed at 159 simple sequence repeat (SSR) loci across 12 rice chromosomes. PCR was carried out in a $25-\mu$ l reaction, and the amplified products were electrophoresed in $4 \%$ polyacrylamide denaturing gel. The microsatellite banding patterns were visualized using the silver staining method (Panaud et al. 1996). QTL analysis for seed awning was further carried out with 38 SSR markers segregating in the $\mathrm{BC}_{3} \mathrm{~F}_{2}$ population (Fig. 2). In addition, two markers of An1-D and LABA1-D, which detect causal mutations at $A n-1$ and $L A B A 1$ loci, respectively, were included in the analysis (Additional file 1: Table S1). A putative QTL was estimated by single marker analysis based on the logarithm of odds (LOD) score using QGene ver.3.0 (Nelson 1997).

\section{Evaluation of Gene Interaction at Seed-Awning Loci}

At a single locus, two homozygous genotypes (IR36 or W630 homozygotes) are expected in the BILs. Since three QTLs were detected for seed awning, a total of eight combinations of homozygous genotypes were examined for gene interaction on seed awning. In each combination, five $\mathrm{BC}_{3} \mathrm{~F}_{3}$ plants were produced from the different $\mathrm{BC}_{3} \mathrm{~F}_{2}$ plants having IR36 chromosomal segments at specific awning loci (Fig. 2). They were grown in the paddy field, and five panicles were collected from each plant at the heading stage. Their awn lengths were measured based on the spikelet positions, and the averages were compared among eight combinations of genotypes together with the parental lines by Tukey's significance test.

Fine Mapping of Seed-Awning Locus on Chromosome 2 The $\mathrm{BC}_{3} \mathrm{~F}_{3}$ progenies were first surveyed based on the marker genotypes at two known seed-awning loci, and a single plant was selected. This plant had loss-of-function alleles at $A n-1$ and $L A B A 1$ loci and the heterozygous chromosomal segment covering the putative QTL on chromosome 2 . It was selfed and the $\mathrm{BC}_{3} \mathrm{~F}_{4}$ plants possessing recombination within the putative QTL region were selected. Progeny test for seed awning was carried out using $\mathrm{BC}_{3} \mathrm{~F}_{5}$ plants derived from the critical recombinants (Fig. 2). The average awn lengths of five plants were compared between two homozygous genotypes by t-test.

\section{Results}

Awn Phenotypes and Marker Genotypes of the J5 Backcross Recombinant Inbred Line

The J5 line showed the shortest awns among 146 BILs at $\mathrm{BC}_{2} \mathrm{~F}_{7}$ generation. Compared with the wild recurrent parent of O. rufipogon W630, the awn length was much 
Table 1 Mean awn lengths $(\mathrm{mm})$ and standard deviation observed for the parental lines, O. sativa IR36, O. rufipogon W630 and the J5 line $(n=5)$

\begin{tabular}{|c|c|c|c|c|c|}
\hline \multirow{2}{*}{ Line } & \multicolumn{5}{|c|}{ Spikelet position } \\
\hline & $1 s t$ & 2nd & $3 \mathrm{rd}$ & 4th & 5 th \\
\hline O. sativa IR36 & $1.4 \pm 0.3$ & $0.0 \pm 0.0$ & $0.0 \pm 0.0$ & $0.1 \pm 0.1$ & $0.5 \pm 0.4$ \\
\hline O. rufipogon W630 & $78.2 \pm 5.1$ & $66.7 \pm 2.5$ & $85.1 \pm 3.7$ & $97.1 \pm 3.5$ & $105.4 \pm 3.1$ \\
\hline \multirow{2}{*}{$\begin{array}{l}J 5 \text { line } \\
\text { (\% length reduction) }^{\text {a }}\end{array}$} & $20.7 \pm 0.9$ & $12.6 \pm 0.3$ & $17.0 \pm 0.4$ & $20.6 \pm 1.6$ & $22.2 \pm 1.8$ \\
\hline & $(73.5 \%)$ & (81.1\%) & $(80.0 \%)$ & $(78.8 \%)$ & (78.9\%) \\
\hline
\end{tabular}

apercentage of length reduction compared to O. rufipogon W630

reduced for all the spikelets in 1 st to 5 th positions; 73.5 $\sim 81.1 \%$ length reduction (Fig. 1, Table 1). The chromosomal constitution was surveyed with 159 molecular markers, and 38 marker loci were found to have homozygous IR36 alleles. They were located on 11 chromosomal segments introgressed into the wild rice from IR36 (Additional file 2: Figure S1).

\section{QTL Analysis for Seed Awning}

In the $\mathrm{BC}_{3} \mathrm{~F}_{2}$ population between the $\mathrm{J} 5$ line and $\mathrm{O}$. rufipogon W630, discontinuous distributions of awn lengths were observed for all the spikelets in the 1 st to 5 th positions (Additional file 2: Figure S2). QTL analysis was carried out with these awn data and the marker genotypes at the 38 loci located on the introgressed segments. As a result, one weak peak was detected on chromosome 2, while a strong peak was detected on chromosome 4. Although the allele effects at the putative QTL on chromosome 2 was small, the peaks were constantly observed for the awn lengths in the 1 st to 5 th spikelet positions $(\mathrm{LOD}=1.9 \sim 3.2, \quad \mathrm{PV}=4.6 \sim 7.7 \%)$ (Table 2). We named the locus qAWNL2 (QTL for awn length on chromosome 2). The QTL region on chromosome 4 contained two major awning loci of $A n-1$ and $L A B A 1$, and IR36 was previously reported to have lossof-function alleles at both loci (Luo et al. 2013; Hua et al. 2015). Therefore, two additional markers of An1-D and LABA1-D detecting these causal mutations were included in the analysis (Additional file 1: Table S1). These markers showed two QTL peaks with high LOD values (An1-D: $18.6 \sim 22.8$, LABA1-D: $24.4 \sim 35.0$ ) in the region (Table 2), indicating that the QTLs on chromosome 4 were identical to $A n-1$ and $L A B A 1$.

\section{Gene Interaction among Three Seed-Awning QTLs}

In this study, high LOD peaks at $q A W N L 2, A n-1$ and $L A B A 1$ were detected for the awn lengths in all the spikelet positions. At these loci, the IR36 alleles had the awnlessness effect in the wild genetic background. Gene interaction among three seed-awning QTLs were further examined with the $\mathrm{BC}_{3} \mathrm{~F}_{3}$ plants having eight different combinations of homozygous genotypes. Here, the eight genotypes were designated by adding three letters of $\mathrm{W}$ or $\mathrm{C}$ in genotypic order at $q A W N L 2, A n-1$ and $L A B A 1$, where $\mathrm{W}$ and $\mathrm{C}$ indicate wild and cultivated homozygous alleles, respectively. In each combination, five plants were selected from the different $\mathrm{BC}_{3} \mathrm{~F}_{2}$ plants based on the linked marker genotypes. Their awn lengths were measured based on the spikelet positions and compared together with the parental accessions (Additional file 2: Figure S3). The average awn length of the 5th spikelet of WWW plants (having wild homozygous alleles at all three loci) was almost the same as that of wild parent W630, whereas a slight length reduction (ca. 12\%) was observed for the CWW plants with IR36 homozygous alleles only at qAWNL2 (Fig. 3). The four genotypes WCW, WWC, CCW, and CWC with IR36 homozygous alleles at either $A n-1$ or $L A B A 1$, showed

Table 2 Putative QTL locations for awnlessness detected in $\mathrm{BC}_{3} \mathrm{~F}_{2}$ population between O. rufipogon W630 and O. sativa IR36

\begin{tabular}{|c|c|c|c|c|c|c|}
\hline Chr. & Locus & Marker $^{a}$ & Source $^{b}$ & Spikelet position ${ }^{c}$ & LOD & $P V^{d}(\%)$ \\
\hline \multirow[t]{5}{*}{2} & qAWNL2 & RM1211 & IR36 & $1 s t$ & 3.2 & 7.7 \\
\hline & & & & 2nd & 2.2 & 5.3 \\
\hline & & & & $3 \mathrm{rd}$ & 2.1 & 5.0 \\
\hline & & & & 4th & 2.0 & 4.9 \\
\hline & & & & 5 th & 1.9 & 4.6 \\
\hline \multirow[t]{5}{*}{4} & $A n-1$ & An1-D & IR36 & $1 s t$ & 20.3 & 39.9 \\
\hline & & & & 2nd & 18.9 & 37.7 \\
\hline & & & & $3 r d$ & 18.6 & 37.2 \\
\hline & & & & 4 th & 21.0 & 40.9 \\
\hline & & & & 5 th & 22.8 & 43.5 \\
\hline \multirow[t]{5}{*}{4} & $\angle A B A 1$ & LABA-D & IR36 & $1 \mathrm{st}$ & 24.4 & 45.7 \\
\hline & & & & 2nd & 35.0 & 58.4 \\
\hline & & & & $3 r d$ & 33.4 & 56.6 \\
\hline & & & & 4th & 28.9 & 51.5 \\
\hline & & & & 5 th & 26.7 & 48.8 \\
\hline
\end{tabular}

${ }^{a}$ Marker giving high LOD by single point analysis

${ }^{b}$ Source of the allele having awnlessness effect

'Spikelet position of awn length data

${ }^{d}$ Percentage of the phenotypic variance explained by the QTL 


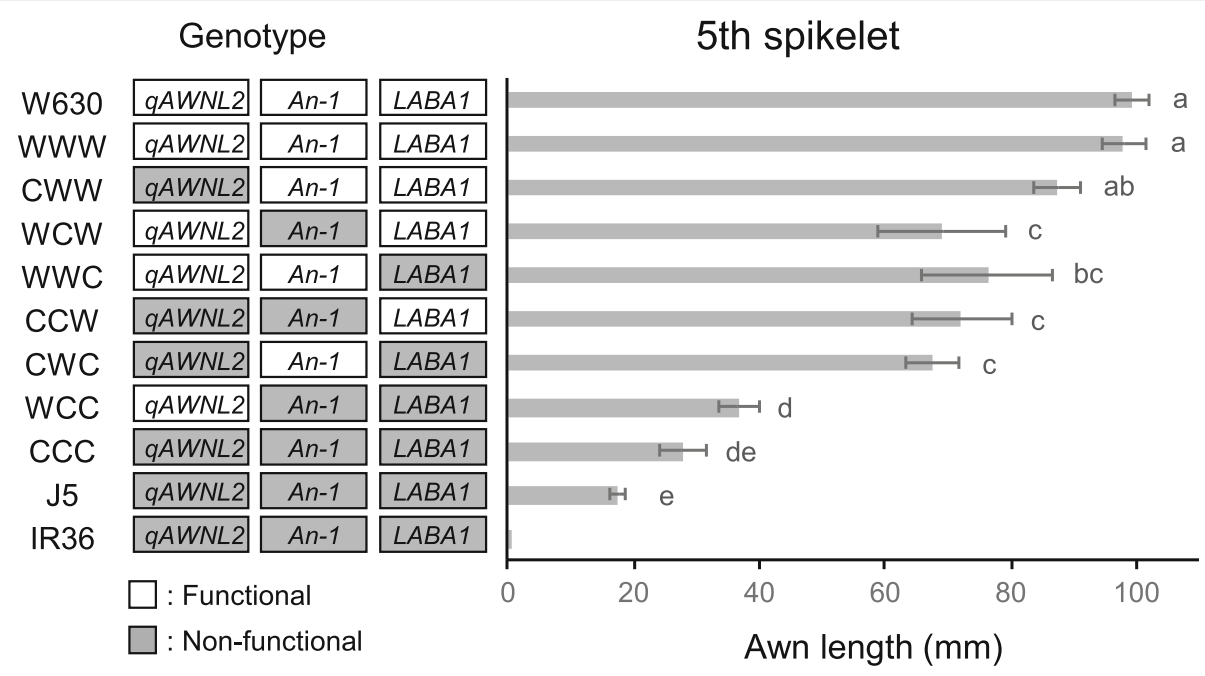

Fig. 3 Awn lengths (means $\pm S D, n=5$ ) of the 5 th spikelets of eight homozygous genotypes in the wild genetic background. These are compared together with the parental accessions of O. rufipogon W630 and the J5 line. Average awn lengths of O. sativa IR36 are shown for reference. Eight genotypes were designated by three-letter combinations of $W$ or $C$ in genotypic order at qAWNL2, An-1 and LABA1, where W and C indicate wild and cultivated homozygous alleles, respectively. White and gray boxes with the locus names beside the genotypes indicate functional (wild) and nonfunctional (cultivated) homozygous alleles, respectively. Means labeled with different letters are significantly different among eight genotypes and two parental lines (Tukey's test, $P<0.05$ )

significant length reduction; around $1 / 3$ shorter than that of W630. The WCC plants with IR36 homozygous alleles at both $A n-1$ and $L A B A 1$ had much shorter awns with about a $2 / 3$ reduction in length. The shortest awn length was observed for the CCC plants having IR36 homozygous alleles at all loci, but it was slightly longer than that of the J5 line. Similar length variation and gene interaction were also detected for the awns of other spikelets in the 1st to 4th positions (Additional file 2: Figure S4). The average awn lengths and percentages of reduction for all the genotypes are summarized in Table 3.

Table 3 Average lengths and reduction percentages of the awns in the 1st to 5th spikelet positions of eight homozygous genotypes and the parental accessions of O. rufipogon W630 and the J5 line

\begin{tabular}{|c|c|c|c|c|c|c|c|c|c|c|}
\hline \multirow[t]{2}{*}{ Position } & \multirow[t]{2}{*}{ W630 } & \multicolumn{8}{|c|}{ Homozygous genotype $^{a}$} & \multirow[t]{2}{*}{$J 5$} \\
\hline & & WWW & CWW & WCW & WWC & CCW & CWC & WCC & $\mathrm{CCC}$ & \\
\hline \multicolumn{11}{|c|}{ Awn length (mm) } \\
\hline $1 s t$ & 71.5 & 70.9 & 59.8 & 54.0 & 57.9 & 53.0 & 51.0 & 29.8 & 24.4 & 16.5 \\
\hline 2nd & 59.3 & 62.8 & 52.8 & 40.4 & 39.6 & 36.8 & 36.6 & 14.9 & 9.9 & 8.1 \\
\hline $3 r d$ & 75.1 & 78.7 & 67.9 & 53.2 & 51.9 & 52.1 & 47.2 & 22.2 & 15.5 & 11.3 \\
\hline 4th & 89.3 & 89.1 & 78.5 & 62.8 & 70.0 & 65.0 & 60.3 & 30.7 & 23.1 & 16.6 \\
\hline 5 th & 99.3 & 98.1 & 87.4 & 69.2 & 76.4 & 72.2 & 67.5 & 36.7 & 27.8 & 17.5 \\
\hline \multicolumn{11}{|c|}{ Perecentage of reduction ${ }^{b}$} \\
\hline $1 s t$ & 0 & 0.8 & 16.4 & 24.5 & 19.0 & 25.8 & 28.7 & 58.4 & 65.9 & 76.9 \\
\hline 2nd & 0 & -5.8 & 10.9 & 31.9 & 33.2 & 38.0 & 38.3 & 74.9 & 83.3 & 86.4 \\
\hline $3 r d$ & 0 & -4.8 & 9.6 & 29.2 & 30.9 & 30.6 & 37.2 & 70.5 & 79.3 & 84.9 \\
\hline 4th & 0 & 0.2 & 12.1 & 29.7 & 21.6 & 27.2 & 32.5 & 65.6 & 74.2 & 81.4 \\
\hline 5th & 0 & 1.2 & 12.0 & 30.3 & 23.0 & 27.2 & 32.0 & 63.0 & 72.0 & 82.4 \\
\hline \multirow[t]{2}{*}{ Average $^{c}$} & 0 & -1.7 & 12.2 & 29.1 & 25.5 & 29.8 & 33.8 & 66.5 & 74.9 & 82.4 \\
\hline & a & a & $b$ & c & c & c & c & $d$ & de & e \\
\hline
\end{tabular}

Eight genotypes were designated by three-letter combinations of $\mathrm{W}$ or $\mathrm{C}$ in genotypic order at $q A W N L 2, A n-1$ and $L A B A 1$, where $\mathrm{W}$ and $\mathrm{C}$ indicate wild and cultivated homozygous alleles, respectively

${ }^{b}$ Length reduction compared to $W 630$

'Overall averages given with different letters are significantly different among the eight genotypes and two parental lines (Tukey's test, $P<0.05$ ) 
Fine Mapping of Seed-Awning Locus, qAWNL2

Although the allele effect at $q A W N L 2$ was weaker than those at $A n-1$ and $L A B A 1$, awn length difference was clearly detected between the WCC and CCC plants. Therefore, a single $\mathrm{BC}_{3} \mathrm{~F}_{3}$ plant (plant no. 146) with cultivated loss-of-function alleles at $A n-1$ and $L A B A 1$ and the heterozygous chromosomal segment containing the $q A W N L 2$ locus was further selfed for fine mapping. The plants displaying recombination within the putative QTL region were surveyed among $580 \mathrm{BC}_{3} \mathrm{~F}_{4}$ plants using a pair of markers, RM5707 and RM6380, and the recombination positions were examined with nine SSR markers located in the putative region (Fig. 4, Additional file 1: Table $\mathrm{S} 1$ ). At the $\mathrm{BC}_{3} \mathrm{~F}_{5}$ generation, the progeny tests were carried out between the lines with the homozygous IR36 and recombinant chromosomal segments derived from the representative recombinants. As a result, two critical $\mathrm{BC}_{3} \mathrm{~F}_{4}$ plants, nos. $146-137$ and $146-17$, were found to have recombination between RM13335 and RM341 and between RM341 and RM13349, respectively (Fig. 4). In the $\mathrm{BC}_{3} \mathrm{~F}_{5}$ plants from no. 146-137, the average awn length of the 5th spikelet of the plants with homozygous recombinant chromosomes ( $\mathrm{R}: 23.8 \mathrm{~mm}$ ) was significantly longer than that with homozygous IR36 chromosomes $(\mathrm{C}: 12.0 \mathrm{~mm})(\mathrm{t}$-test, $P<0.01)$. The significant length differences $(P<0.01)$ were also observed between the two homozygous groups for the 1st to 4th positions of the spikelets (Additional file 1: Table S2). In contrast, no significant differences in awn lengths were observed for any positions of spikelets between two homozygous $\mathrm{BC}_{3} \mathrm{~F}_{5}$ genotypes $(\mathrm{C}$ and $\mathrm{R})$ derived from no. 146-17 (Fig. 4, Additional file 1: Table S2). These progeny tests indicate that the candidate region of qAWNL2 was within a 157.4-kb region between RM13335 and RM13349. In this region, a total of 22 genes were predicted based on the sequence annotation for O. sativa Japonica Nipponbare by RAP-DB (Additional file 1: Table S3) (Sakai et al. 2013). Further investigations are necessary to specify the gene of $q A W N L 2$.

\section{Discussion}

\section{Evaluation of Seed Awning}

Seed awning is one of the wild-specific traits in rice. In order to detect the responsible loci for this trait, several QTL analyses have been carried out using interspecific populations between wild accessions and cultivars (Xiong et al. 1999; Cai and Morishima 2002; Thomson et al. 2003; Gu et al. 2005). In these studies, seed awning was evaluated based on the presence/absence of awns or the average awn length of seeds. The former evaluation is unstable because the awn phenotype usually shows a continuous distribution in the interspecific populations. The latter evaluation does not consider the awn length variation caused by the spikelet position in the panicle.

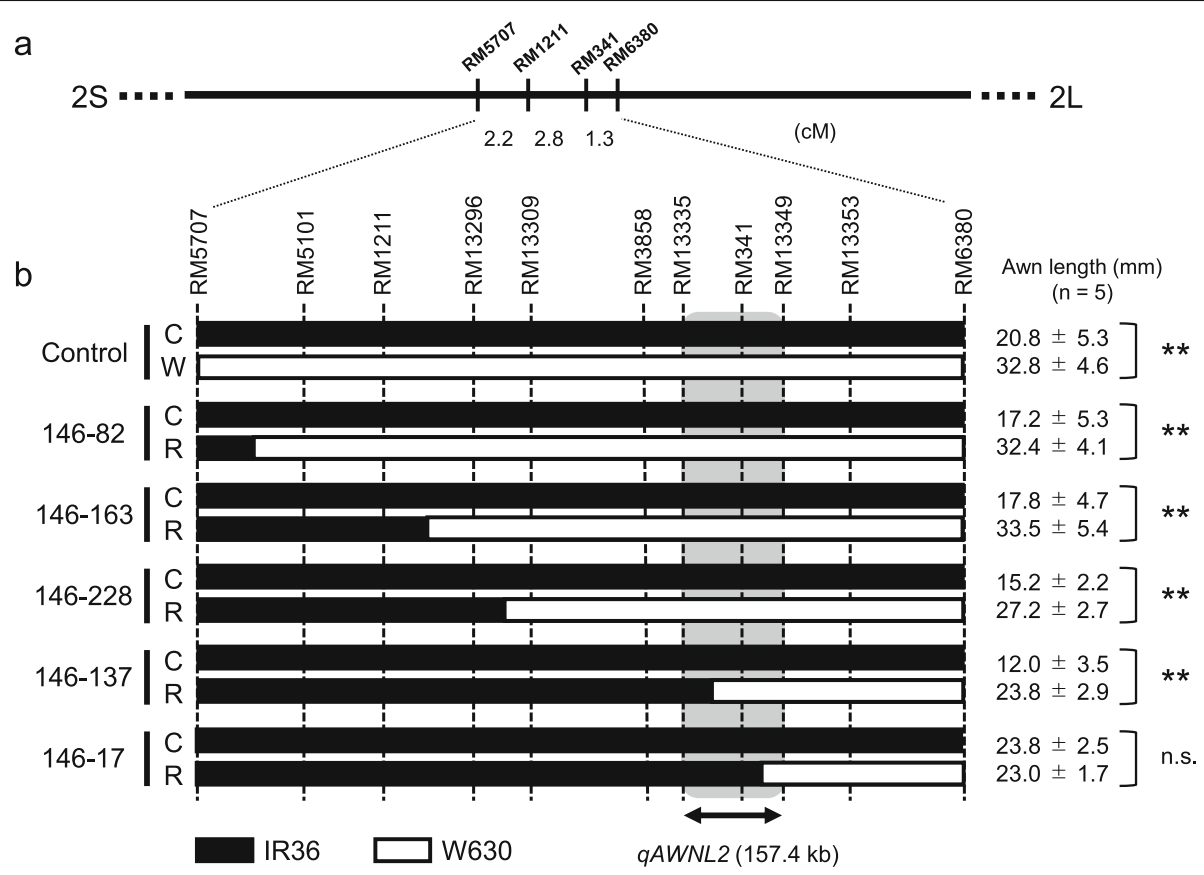

Fig. 4 Fine mapping of GAWNL2. a Molecular markers between RM5707 and RM6380 on chromosome 2 were used to detect recombinants near the qAWNL2 locus. $\mathbf{b}$ Graphical genotypes of $\mathrm{BC}_{3} \mathrm{~F}_{5}$ lines derived from five critical recombinant $\mathrm{BC}_{3} \mathrm{~F}_{4}$ plants (nos. 146-82, $-211,-228,-137$ and - 17) in the candidate region of qAWNL2. C, W and R: Homozygous IR36, W630 and recombinant chromosomes, respectively. Awn lengths (means $\pm S D, n=5$ ) of the 5 th spikelets of the $B_{3} F_{5}$ lines are shown on right. ${ }^{* *}$ and n.s.: significant at $P<0.01$ and not significant, respectively. The qAWNL2 locus was estimated in the 157.4-kb region between RM13335 and RM13349 
Therefore, only the major loci explaining high phenotypic variance could be detected in these analyses. Their wild alleles with strong awning effects were further investigated in the genetic background of cultivated rice, and three genes at $A n-1, L A B A 1$ and RAE2, were identified (Luo et al. 2013; Hua et al. 2015; Bessho-Uehara et al. 2016). However, other minor loci were not detected because of the rough evaluation methods. In general, awn length varies according to the position of the spikelet in the panicle (Table 1), and the numbers of seeds and primary/secondary branches are different among the plants. Therefore, in this study, awn lengths were compared between spikelets in the same position on the top primary branch for the precise evaluation. As a result, a minor locus of $q A W N L 2$ was detected in the QTL analysis, and the chromosomal location was successfully estimated by the progeny test.

\section{Allele Effects of Seed Awning in the Genetic Background of Wild Rice}

The awning effects of wild functional alleles at major loci are easy to detect in the genetic background of cultivated rice. Conversely, the cultivated loss-of-function alleles are difficult to evaluate in the wild genetic background where many other wild awning genes are expressed. Therefore, cultivated allele effects of awnlessness were examined with different combinations of genotypes at three awning loci, $A n-1, L A B A 1$ and $q A W N L 2$. For all the genotypes, awn length variations in the panicles were observed, but their length reduction ratios were similar for the 1st to 5th spikelets (Table 3). The significant differences among the overall averages (1st to 5 th) of length reduction revealed by Tukey's test suggest that genotype combinations at three loci have a wide influence on the awn length in the panicles.

The overall averages of length reduction of the CWW, WCW and WWC genotypes were 12.2\%, 29.1\% and $25.5 \%$, respectively. These ratios directly explain the awnless effect of loss-of-function allele at either locus. Namely, the IR36 alleles at two major loci, $A n-1$ and $L A B A 1$, reduced the awn length of W630 by $25-30 \%$, while those at $q A W N L 2$ had a weak effect $(12.2 \%$ reduction). Among the IR36 alleles at these loci, additive effects were clearly observed for length reduction. The CCW and CWC genotypes showed slightly higher reduction ratios than the WCW and WWC genotypes, respectively. A $2 / 3$ reduction ratio $(66.5 \%)$ was observed for the awn length of the WCC plants. The CCC plants accumulating loss-of-function mutations at all loci had the highest length reduction of $74.9 \%$, corresponding to about $90 \%$ of awnlessness of the J5 line $(82.4 \%$ reduction). Since the J5 line still had short awns, the complete awnlessness in IR36 may be generated by additional accumulation of loss-of-function mutations at minor loci.

\section{Awnlessness in the Cultivated Rice}

Until now, three major loci, An-1, LABA1 and RAE2, have been reported for seed awning, and their wild alleles have a strong awn-elongation effect (Luo et al. 2013; Hua et al. 2015; Bessho-Uehara et al. 2016). In this study, a reduction of about $66 \%$ in awn length was explained by the loss-of-function alleles at two major loci of $A n-1$ and $L A B A 1$, and a cumulative $75 \%$ reduction was attained with the additional allele effect at $q A W N L 2$. Interestingly, no QTL was detected around $R A E 2$ region on chromosome 8 . This may be due to the fact that the IR36 allele is functional at RAE2. Previously, we examined awnlessness using the backcross population between O. rufipogon W630 and O. sativa Nipponbare (Ikemoto et al. 2017). Two major loci, $A n-1$ and RAE2, were detected by QTL analysis in the genetic background of wild rice. No QTL was found around $L A B A 1$ locus, because Nipponbare has the functional allele at $L A B A 1$ (Hua et al. 2015). These results indicate that the awnless characters of IR36 and Nipponbare are achieved by loss-of-function alleles at two of three major loci and some minor loci. Namely, the complete suppression of awn elongation may not require the mutations at all three major loci, $A n-1, L A B A 1$ and RAE2. Probably, certain combinations of mutations are associated with the awnless phenotypes of cultivars.

\section{Conclusions}

This study investigates the domestication loci associated with awnlessness in cultivated rice, O. sativa. QTL analysis revealed that three loci, $A n-1, L A B A 1$ and $q A W N L 2$, were mainly responsible for the awnlessness of O. sativa IR36. In the initial phase of rice domestication, long awns may be beneficial for seed gatherers, because they enhance the collection efficiency. The selection for shorter awns may have started after the emergence of non-seed-shattering plants. In the wild genetic background, loss-of-function alleles at three awning loci showed additive effects on length reduction. Therefore, awnless forms may be gradually generated through the accumulation of mutations at awning loci. Once a series of key awning loci are determined, the combination of mutations among awnless cultivar groups will be useful in clarifying the process and history of rice domestication in detail.

\section{Supplementary information}

Supplementary information accompanies this paper at https://doi.org/10. 1186/s12284-020-00386-4.

Additional file 1: Table S1. Additional molecular markers used for QTL analysis and fine mapping. Table S2. Average awn lengths ( $\mathrm{mm})$ and standard deviation observed for the homozygous genotypes derived from the recombinants $(n=5)$. Table S3. List of genes annotated in a 157.4-kb candidate region of qAWNL2, by the RAP-DB. 
Additional file 2: Figure S1. Graphical genotype of the J5 backcross recombinant inbred line. Figure S2. Frequency distributions of awn lengths in the 1st to 5 th spikelet positions in $\mathrm{BC}_{3} \mathrm{~F}_{2}$ population between O. rufipogon W630 and the J5 line. Figure S3. Spikelet morphology of the eight genotypes of $\mathrm{BC}_{3} \mathrm{~F}_{3}$ plants together with $\mathrm{O}$. rufipogon W630, J5 line and $O$. sativa IR36. Figure S4. Awn lengths (means \pm SD) of the 1st to 4th spikelets of eight homozygous genotypes in the wild genetic background.

\section{Abbreviations}

BIL: Backcross recombinant inbred line; LOD: Logarithm of odds;

QTL: Quantitative trait locus; SSR: Simple sequence repeat

\section{Acknowledgements}

We thank the National Institute of Genetics (National Bioresource Project), Japan, for providing the seeds of wild rice.

\section{Authors' contributions}

$\mathrm{TI}$ conceived and designed the research. TI, YPJA and RK performed the field experiments. YPJA, RK, AN and PDTP contributed to the genotyping. TI, YPJA and RI analyzed the data. TI, YPJA and RI prepared the manuscript. All authors read and approved the final manuscript.

\section{Funding}

This work was supported in part by a Grant-in-Aid (No. 18H02178) and Bilateral Program (JPJSBP120189948) from Japan Society for the Promotion of Science.

\section{Availability of data and materials}

All data supporting the conclusions described here are provided in tables and figures.

\section{Ethics Approval and Consent to Participate}

Not applicable.

\section{Consent for publication}

Not applicable.

\section{Competing interests}

The authors declare that they have no competing of interests.

\section{Author details}

'Graduate School of Agricultural Science, Kobe University, 1-1 Rokkodai, Nada-ku, Kobe 657-8501, Japan. ${ }^{2}$ Present address: Research Institute for Biotechnology and Environment, Nong Lam University, Ho Chi Minh, Vietnam.

Received: 27 February 2020 Accepted: 14 April 2020

Published online: 28 April 2020

\section{References}

Bessho-Uehara K, Wang DR, Furuta T, Minami A, Nagai K, Gamuyao R, Asano K, Angeles-Shim RB, Shimizu Y, Ayano M, Komeda N, Doi K, Miura K, Toda Y, Kinoshita T, Okuda S, Higashiyama T, Nomoto M, Tada Y, Shinohara H, Matsubayashi Y, Greenberg A, Wu J, Yasui H, Yoshimura A, Mori H, McCouch SR, Ashikari M (2016) Loss of function at RAE2, a previously unidentified EPFL, is required for awnlessness in cultivated Asian rice. Proc Natl Acad Sci U S A 113:8969-8974

Cai W, Morishima H (2002) QTL clusters reflect character associations in wild and cultivated rice. Theor Appl Genet 104:1217-1228

Dellaporta SL, Wood H, Hicks JB (1983) A plant DNA minipreparation. Plant Mol Biol Report 1:19-21

Fuller DQ, Allaby R (2009) Seed dispersal and crop domestication: shattering, germination and seasonality in evolution under cultivation. Annu Plant Rev 38:238-295

Gu XY, Kianian SF, Hareland GA, Hoffer BL, Foley ME (2005) Genetic analysis of adaptive syndromes interrelated with seed dormancy in weedy rice (Oryza sativa). Theor Appl Genet 110:1108-1118

Harlan JR, de Wet JM, Price EG (1973) Comparative evolution of cereals. Evolution 27:311-325
Htun TM, Inoue C, Chhourn O, Ishii T, Ishikawa R (2014) Effect of quantitative trait loci for seed shattering on abscission layer formation in Asian wild rice Oryza rufipogon. Breed Sci 64:199-205

Hua L, Wang DR, Tan L, Fu Y, Liu F, Xiao L, Zhu Z, Fu Q, Sun X, Gu P, Cai H, McCouch SR, Sun C (2015) LABA1, a domestication gene associated with long, barbed awns in wild rice. Plant Cell 27:1875-1888

Ikemoto M, Otsuka M, Thanh PT, Phan PDT, Ishikawa R, Ishii T (2017) Gene interaction at seed-awning loci in the genetic background of wild rice. Genes Genet Syst 92:21-26

Ishii T, Ishikawa R (2018) Domestication loci controlling panicle shape, seed shattering and seed awning. In: Sasaki T, Ashikari M (eds) Rice genomics, genetics and breeding. Springer Nature, Singapore

Ishii T, Numaguchi K, Miura K, Yoshida K, Thanh PT, Htun TM, Yamasaki M, Komeda N, Matsumoto T, Terauchi R, Ishikawa R, Ashikari M (2013) OsLG1 regulates a closed panicle trait in domesticated rice. Nat Genet 45:462-465

Ishikawa R, Thanh PT, Nimura N, Htun TM, Yamasaki M, Ishii T (2010) Allelic interaction at seed-shattering loci in the genetic backgrounds of wild and cultivated rice species. Genes Genet Syst 85:265-271

Khush GS, Virk PS (2005) IR varieties and their impact. International Rice Research Institute, Los Banos

Konishi S, Izawa T, Lin SY, Ebana K, Fukuta Y, Sasaki T, Yano M (2006) An SNP caused loss of seed shattering during rice domestication. Science 312:1392-1396

Li C, Zhou A, Sang T (2006) Rice domestication by reducing shattering. Science 311:1936-1939

Luo J, Liu H, Zhou T, Gu B, Huang X, Shangguan Y, Zhu J, Li Y, Zhao Y, Wang Y, Zhao Q, Wang A, Wang Z, Sang T, Wang Z, Han B (2013) An-1 encodes a basic helix-loop-helix protein that regulates awn development, grain size, and grain number in rice. Plant Cell 25:3360-3376

Nelson JC (1997) QGENE: software for marker-based genomic analysis and breeding. Mol Breed 3:239-245

Oka HI (1988) Origin of cultivated rice. Elsevier, Amsterdam

Panaud O, Chen X, McCouch SR (1996) Development of microsatellite markers and characterization of simple sequence length polymorphism (SSLP) in rice (Oryza sativa L.). Mol Gen Genet 252:597-607

Sakai H, Lee SS, Tanaka T, Numa H, Kim J, Kawahara Y, Wakimoto H, Yang C, Iwamoto M, Abe T, Yamada Y, Muto A, Inokuchi H, Ikemura T, Matsumoto T, Sasaki T, Itoh T (2013) Rice annotation project database (RAP-DB): an integrative and interactive database for rice genomics. Plant Cell Physiol 54 https://doi.org/10.1093/pcp/pcs183

Thomson MJ, Tai TH, McClung AM, Lai XH, Hinga ME, Lobos KB, XU Y, Martinez CP, McCouch SR (2003) Mapping quantitative trait loci for yield, yield components and morphological traits in an advanced backcross population between Oryza rufipogon and the Oryza sativa cultivar Jefferson. Theor Appl Genet 107:479-493

Vaughan DA, Balazs E, Heslop-Harrison JS (2007) From crop domestication to super-domestication. Ann Bot 100:893-901

Xiong LZ, Liu KD, Dai XK, Xu CG, Zhang Q (1999) Identification of genetic factors controlling domestication-related traits of rice using an $\mathrm{F}_{2}$ population of a cross between Oryza sativa and O. rufipogon. Theor Appl Genet 98:243-251

Zeigler RS, Barclay A (2008) The relevance of rice. Rice 1:3-10

\section{Publisher's Note}

Springer Nature remains neutral with regard to jurisdictional claims in published maps and institutional affiliations. 